\title{
"It was just natural": aggression in New Zealand kitchens
}

\section{Scott Wright}

Scott Wright is a chef lecturer in culinary arts at Auckland University of Technology, New Zealand. Scott has 30 years of industry experience and recent experience researching celebrity chefs and the construct of compulscelebrity.

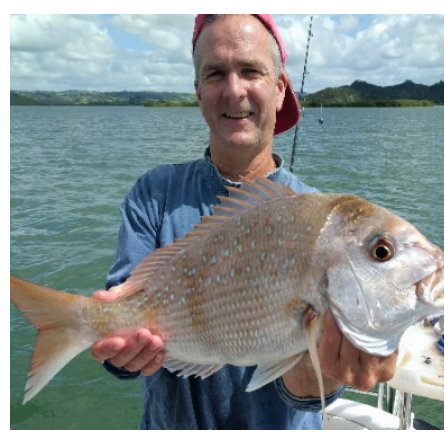

A commercial kitchen can be an aggressive environment. Research on aggression in kitchens and the hospitality sector is important as it illuminates environmental, vocational and cultural issues. This article explores how upmarket chefs, many of whom are now proprietors, have experienced aggression. Information for this article was collected during a wider study on how the impact of compulsory celebrity within kitchen culture has affected upmarket chef proprietors [1]. Its contribution is in providing a New Zealand context to research on kitchen aggression. Data were analysed, grouped and coded using grounded theory methods, which allow findings to be extracted from the data without using any preconceived theoretical framework [2]. Analysis revealed that all chefs had experienced aggressive behaviour or had been the perpetrators themselves. Research such as this hopes to encourage frank discussion that can demystify aggression and reduce harm.

Aggressive behaviour within kitchens can be faced by all, including kitchen workers, front of house staff, management, proprietors and suppliers. It can be a factor in poor staff morale and result in staff turnover [1,3]. The inclination for a person to act aggressively in a kitchen can be influenced by environmental conditions including an uneven workload, low margins, poor wages, irregular working hours, and difficult working conditions such as insufficient space and heat. All of these factors create an 'aggression-ready' environment [4]. Further, kitchens are hierarchical in structure with those who may be the most susceptible to aggressive acts also being those least likely to have the confidence, status or ability to voice their concerns. It takes years of training to be a chef, and it is during this process that aggression is most likely to be experienced [5]. Well-known chef Gordon Ramsay calls this "the knowledge", stating: "this job is the pits when you're learning. You have to bow down and stay focused until the knowledge is tucked away ... The weak disappear off the face of the earth" [6]. However, aggression within kitchens is now being publicly discussed, with websites such as 'FairKitchens' (https://www.fairkitchens.com) spotlighting negative kitchen culture and creating a space for shared stories and industry unity. Other research is taking place, such as the five-year-funded, Australian-wide industry study focusing on the mental health of chefs and examining adverse practices within kitchen culture [7]. Initiatives and research such as this seek to contribute to real-world solutions.

The research above strongly suggests that the culture and environmental 
conditions that result in aggressive acts in commercial kitchens are real. From a New Zealand perspective, all 20 chefs interviewed had experienced aggression. Reflecting on his early vocational experiences, one interviewee, James, stated: "It was a tough environment; I got my hand fractured by one of the head apprentices with one of those big wooden spoons. Probably I said something I shouldn't of. I got hit. However, I thrived in it." Troy supported the assumption that part of the learning involved accepting physical aggression: "It was discipline. We didn't think about it like being hit, you expect it, but it taught you, because you had to be perfect all the time." Because this research focussed on chef proprietors, these comments may reflect a time when aggression was seen as an important part of being a chef. However, with experience and on reflection, several participants lamented their own aggressive actions. June stated, "It was just natural ... I stomped on a lot of people. I thought that everybody else wanted to get to the top so therefore I was probably harsher on people than what I needed to be."

Some chefs now focus on their own and their staffs' general well-being. Jeremy discussed that, "I always like to work with people that didn't yell and scream. I don't think that's appropriate in a kitchen because it is already hard enough. Without some chef yelling and screaming at you ... staff are the most important." These statements perhaps reflect a desire, a need, and the will for kitchen cultural change. Additionally, it shows the importance of educating individuals entering the commercial kitchen environment about the stressors that they will face and how to deal with them, with the aim of reducing the occurrences, severity and overall harm that aggressive acts cause. It is only through the education and support of young chefs entering kitchens, and acknowledgement by more experienced chefs that the kitchen culture needs to change, that lasting benefits for all will occur.

Read the full research here: https://openrepository.aut.ac.nz/handle/10292/9559

\section{Corresponding author}

Scott Wright can be contacted at: scott.wright@aut.ac.nz

\section{References}

(1) Wright, S. D. The Compulcelebrity Effect: Upmarket Chef Proprietors and Compulsory Celebrity. Master's Thesis, Auckland University of Technology, 2015. https://openrepository.aut.ac.nz/handle/10292/9559 (accessed Nov 25, 2017).

(2) Díaz-Andrade, A. (2009). Interpretive Research Aiming at Theory Building: Adopting and Adapting the Case Study Design. The Qualitative Report 2009, 14 (1), 42-60. https://nsuworks.nova.edu/tqr/vol14/iss1/3

(3) Johns, N.; Menzel, P. J. (1999). If You Can't Stand the Heat!: Kitchen Violence and Culinary Art. Hospitality Management 1999, 18 (2), 99-109. https://doi.org/10.1016/S0278-4319(99)00013$\underline{4}$

(4) Meloury, J.; Signal, T. (2014). When the Plate is Full: Aggression among Chefs. International Journal of Hospitality Management 2014, 41, 97-103. https://doi.org/10.1016/j.ijhm.2014.05.006

(5) James, S. (2006). Learning to Cook: Production Learning Environment in Kitchens. Learning Environments Research 2006, 9 (1), 1-22. https://doi.org/10.1007/s10984-005-9001-5

(6) Duncan, A. Andrew Duncan Meets Gordon Ramsay. Radio Times Feb, 2001, 10 (16), 8-12.

(7) Robinson, R.; Whitelaw, P.; Lyman, D.; Rogers, L. (2019). Are Things Just Too Hot in the Kitchen? Chefs' Mental Health \& Wellbeing. Presented at the Travel and Tourism Research Association Conference, June 25-27, Melbourne, Australia. 